\title{
The development of a structural equations model for the factors that influence effectiveness in public transportation schedule management
}

\author{
Namchoke Somapa \\ Opal Suwunnamek
}

King Mongkut's Institute of Technology Ladkrabang, Thailand

\section{Key words}

Business environment, Organization factor, RFID, Technology, Efficiencies, Performance

\begin{abstract}
This research study aimed to examine the development and testing of consistency for a model designed to evaluate the structure of effectiveness in public transportation schedule management using radio frequency identification (RFID) technology in Thailand. The public transportation system is very important to Thailand's development, especially with regards to socio-economic aspects. This study used a quantitative research methodology and quantitative analysis to obtain the results. The participants comprised 320 RFID industrial entrepreneurs in Thailand selected by stratified random sampling, and the distributed questionnaires were analyzed using structural equation analysis. The research found that the testing of the structural relationship showed the effectiveness of public transportation by using RFID in Thailand. The consistency of the model was analyzed by chi-square $=\chi 2 / d f=1.348$ GFI $=0.972$ AGFI $=0.947$ CFI $=1.00$ $R M S E A=0.033$ to show that the model was consistent with the empirical data. This research study indicated that the business environment is an important factor that influences public transportation management in Thailand by using RFID to manage transportation systems, which would reduce production costs in business, operating hours, transportation time, and also enable observation of real-time operating hours and application of the system to develop production and other operating systems.
\end{abstract}

Corresponding author: Namchoke Somapa

Email address for corresponding author: namchokekmitt@gmail.com

First submission received: $1^{\text {st }}$ May 2018

Revised submission received: $5^{\text {th }}$ July 2018

Accepted: $12^{\text {th }}$ August 2018

\section{Background and Significance of the Problem}

Nowadays, applying new technology; such as, Internet-capable devices to mass transportation and public transportation systems can enhance support and service users to have more convenience, security and confidence in using the provided services. This concept supports the organizational objective of applying radio frequency identification (RFID), which is a well-known and universal technology for the management of business and activities of daily living at the present time. Moreover, RFID can be applied to various business and industry activities; such as, retail, wholesale, production, the supply chain, security and access control, barcode replacement, biological records, and animal tracking among others.

RFID is an electronic data record system that is able to calculate and enhance the safety of information as well as enable the transfer of information with electronic magnetic waves instead of physical attachment. Accordingly, this increases convenience and reduces the steps of storing and checking the data in the original documents. The use of information technology is accepted by individuals and organizations as a way to analyze human behavior and as an option for describing attention as well as forecasting human behavior in the acceptance of information technology (Chaveesuk and Wongjaturaphat, 2012).

Presently, RFID is used in supply chain management and logistics for businesses and factories. Various products use a RFID system in processing, especially for management, product distribution and services, which helps in reducing the steps and any complications as well as increasing convenience for management. As RFID takes a larger role in supply chain and logistics management, the popularity of 
using barcodes would decrease because of the qualifications of the memory chip, which would have a higher operating ability together with the logistics-related processes. These features are being considered in free trade agreements (FTA) to reduce the complexity of document management systems. This may cause a price competition to replace the barcode system. Singkarin and Somboonwiwat (2010) stated that nowadays scientific technology and innovations are important mechanisms for the changes occurring in the economy, society, and politics. This makes it doubly important for the economy to recall development in all concerned countries around the world. The technological capability that has been developed is a major factor in maintaining or enhancing cooperation and national competitiveness. Although Thailand's industries have been developing for more than four decades and created a high potential for the use of technology, science and technological knowledge cannot be extended to create innovations, especially technological innovations that are significant factors of business competition. Therefore, organizations of all sizes in production, the service or the public sectors are depending on technologies and also have to maintain their business status at the international level to compete with one another using intellectual capital.

Currently, mass public transportation systems have become more diverse with buses, taxis, boats, vans, etc. Nonetheless, buses are considered the main service used in public transportation systems, and they are also very important for Thailand's transportation system. However, there are problems and barriers in regular service use. One of the problems is based on the amount of traffic and the rapid service of bus drivers, which have resulted in a lack of effectiveness in service potential and caused risks to the passengers using the services. This issue appears in the news frequently in Thailand; such as, buses not stopping at the bus stop, making the passenger get on and off in the middle of the street, or the bus driver does not stop at every bus stop, so passengers cannot take the bus. Another problem for passengers is that there are no fixed time schedules for the buses at the bus stops; thus, this causes inconvenience due to long waiting periods at the bus stop. The problems mentioned are caused by the inefficiency of the control system. If there was an enhanced public transportation management system, this would result in higher security and a better-quality service by the bus system.

From all of the significant factors stated, the researcher became interested in the development of a structural equations model (SEM) for the factors that influence the effectiveness of public transportation schedule management in Thailand by using RFID. From the literature review, past research indicated that using materials and information technology, especially Internet technology, with public transportation development and mass public transportation systems to enhance effectiveness would help passengers and service users to gain more convenience, security, and confidence in service usage. Therefore, it is significant to apply the objectives of the organizational process in RFID use and influence the employees to meet the satisfaction of customers (Olowokudejo et al., 2011). This would also increase the ability for customer support teams to provide better service quality and customer response time (Anderson, 2006; Nguyen et al., 2007).

Land transport in Thailand is one the most popular and important aspects of the economic system. At present, government agencies are trying to develop and manage mass transit systems through the application of technology. RFID technology is also important for mass transit systems in Thailand, as it can be beneficial for consumers, land transport operators, and for application in logistics and other industries, respectively (Ilie-Zudor et al., 2011; Löfgren et al., 2008). Due to economic expansion, factories are located in various regions resulting in labor migration and employment; as such, people can earn an income and have a better quality of life. However, the problems of traffic jams, commuting time including the traveling routes have not been improved to cover all areas. Therefore, these are still issues, which the government sector should urgently improve and develop. Thus, this research was conducted to assist in responding to the gaps of the aforementioned problems with the introduction of RFID technology that could be applied in the management of the mass transit systems for maximum benefits. 


\section{Conceptual Development Effectiveness}

The effectiveness of public transportation schedule management can be improved by using RFID, which is a universal and popular technology. This technology can also highly benefit businesses and the daily living of human beings. This is because RFID can be applied in various activities; such as, retail and wholesale businesses, production, supply chains, logistics systems, security and access control, barcode replacement, historical records, and animal tracking among others. RFID is electronic data collection that is able to calculate and keep information secure as well as enable use of electric magnetic waves for sending and receiving information instead of physical attachment. As a consequence, this causes improved convenience for users and also reduces the steps needed for storing and checking information in the original format of documents.

For the development of a mass transportation system to reach higher effectiveness and provide better services, convenience, and speed as well as be more affordable for users, all related organizations in both the public and private sectors should place significance on this topic. This would include: 1) fast service meaning services must provide the exact details; such as, the number of the service usage and the commuting time in each direction, as well as enhance problem resolution at intersections by building roads, bridges, tollways and extension of routes to support a faster commuting time in both personal vehicles and public transportation (Bangkok Environment Agency, 2009); 2) saving traveling expenses on mass transportation use could be conducted in two ways: A) Saving the cost of transportation expenses in which the entrepreneurs or the service providers would have to provide good management to give the lowest cost with good service quality. When the travel rate is lower, the cost would be lower as well. B) Saving on travel costs, which is the service users responsibility. When the fee is cheaper, this causes a lower cost of living. If public transportation provides a good service, this would affect the quality of life for service users. Finally, this can increase the number of service users. 3 . The safety of the public transportation because it is a service used by many people, so full attention must be provided on the security of all vehicle drivers and their service by controlling the speed of the bus. This can reduce accidents and raise the value of belonging to security for the service users. 4) The quantity of vehicles in mass public transportation nowadays is insufficient to support the needed services. People, especially in Bangkok, account for more than five million users per day. When there are insufficient services to meet satisfaction, this causes a crowded environment, which in turn causes both land and water commuting issues. This affects the security of service users.

However, accidents from public transportation constantly happen and cause the loss of life and property. If there were enough vehicles for public transportation services, this would help support the security of service users better (ibid). For the promptness of the service schedule, this problem occurs because of the inconsistency of the schedule causing service users to infrequently organize the traveling time. As a result, people prefer using their personal cars, which may increase traffic. Thus, development in this aspect should result in less problems and support users to set up their traveling time effectively. This could establish the improvement of the commuting time, which is consistent with the study of Ngamsukkasemsri and Wiangharuthai (2011), who assessed the development of the effectiveness for truck management with RFID for use in the food industry. Thai business owners are interested in using RFID more and more these days as well as the systems design and hardware materials. Software developed by Thai innovators is making the systems flexible and suitable for industrial working conditions and the logistics systems in Thailand. Thus, RFID would enhance the ability to support the needs of customers effectively causing improved services and reducing the cost for service providers and users.

\section{Business Environment}

All businesses, local and international, have high competition and should be able to measure their efficacy. Success or failure is dependent on the environment, especially for businesses operating these days that face constant rapid changes in the business environment. Businesses need to adjust to the changing environment, which is a challenge for administrators in following and understanding how to set 
up a processing plan consistent with the environment (Margarietha, 2007). The business environment is the factor causing an impact on the processing plan of organizations. On the other hand, it can also improve the impact of the said plan (Covin and Slevin, 1990, as cited in Hornsby, 2002). The element of the business environment is the factor of the environment inside the organization causing the impact on the organization's owners (Hornsby et al., 2002). Moreover, the factors of the business environment include the internal and external influences for the business owners (Margarietha, 2007). In summary, the business environment is a subject that influences business processes in the organization. Alternatively, this can also affect the business processes, which is divided into two sections: internal environmental organizations, financial resources, engines, buildings, and operations of the organization; such as, the competition, clients, economic factors, politics and society.

Erumegbe (2015) stated that the environment can be separated into two types: the internal and external conditions. Consequently, it has been found that the business environment influences the effectiveness of organizational management. From the literature review, there were studies of the relationship between the business environment and organizational factors. Ansoff and McDonell (1990), Babatunde and Adebisi (2012), and Johnson et al. (2002) found that the business environment was related to the effectiveness of organizational management for developing into being a better organization (Berger and Forgette-Gironde, 2012). Significant people are the leaders who can promote the organizations to success using strategic planning together with development. The leaders of the changes have certain behaviors showing that they are not limited by the perceptions of the factors. Instead, they focus on work change or adjusting the model from the suggestions of the employees as well as improvement and application beyond the team's expectations (Bass, 1998). Changes will try to make the organization develop and use new ways of management to support the customer service promptly and meet the needs of customers (Kaasinen, 2009). From the literature review, the hypotheses for this present research are as follows:

Hypothesis 1: The business environment influences organizational factors.

Hypothesis 2: The business environment influences the acceptance of the use of technology.

\section{Organizational Factors}

Organization is the result of human behavior gathered in a group to perform activities in order to answer their needs; such as, the social gathering in ancient times for hunting purposes or building shelters. This type of gathering also built up the relationship between the individual in that group by using gathering as a tool to identify the relationship status, which changed into an organizational pattern afterwards. As an organization, people gather for some benefits more than just basic human instinct. As such, the organization has major roles in all human activities; namely, business, religion, education or even in transportation.

The organization role can be identified from 1) the Environmental Condition, which happens from the transformation of the Rural Culture to the Urban Culture that creates intimacy, interdependence, conflict and leads to the origin of the organization as a tool to shape human relationships. 2) Human Condition, which motivates people to create a new organization from their knowledge in identifying the relationship in order to receive the benefit from the operation. 3) Organization Condition, which happens after the organization has been established for a certain period; there would be some organizational culture that would result in continuous change as a means to adjust to the environment, both internally and externally, to reserve the resources, and 4) Social Condition, which is presented as various social evolutions; such as. technology evolution, education evolution, as well as the increasing of population that causes the organization to expand to answer the increasing needs of humans. Moorhead and Griffin (1995) provided a definition of organization as the group of people who work together to achieve the same goal. This also confers with Gibson et al. (1994) who identified organization as a cooperative unit consisting of two or more people working in coordination to accomplish the same target. Hence, the organization needs to have a high level of cooperation because the employees would tend to have various abilities; namely, professional employees, technique operation personnel and service support staff. As such, the organization would need to be designed perfectly for everyone with different skills, abilities and roles to 
cooperate efficiently and effectively. According to Wheelen and Hunger (2012), the major factors that organizations need are 1) quality human resources, 2) management strategy, and 3) organizational technology.

Each organization contains various types of people working together wherein both the employees and the organization have interrelations in which the organization expects the efforts, abilities, loyalty, skills, time devotion and full potentiality from the employees. Meanwhile, the employees expect payment, job stability, benefits, job opportunities, job status and job development. If both the employees and organization receive what they expect appropriately and fairly, this would create a satisfactory and beneficial relationship. In a business that needs to adjust to change, if the executive lacks competence in setting the strategies and working according to the pre-planned design, the business will fail. As such, the executives in most organizations see the importance of setting the strategy and the planning procedures including the experts who have to understand the concepts of basic strategic management. Martins and Terblanche (2003) defined strategy as the motivational behavior mechanism that encourages drive and open communication. It is a factor of organizational culture that influences creativity and innovation. The standard norm and beliefs also have major roles in creativity and innovation and can encourage or restrain the creativity and innovation depending on various influences. Kinyua's (2015) study found that organizational factors and the using of information technology in the organization could reduce the costs of the business operation. Furthermore, government organizations that utilize outsourced technology in their mega projects could reduce the costs (Segal et al., 2003). Thus, the literature review resulted in the following hypotheses:

Hypothesis 3: The organizational factors affect the efficiency of bus schedules management using radio frequency identification systems.

Hypothesis 4: The organizational factors affect the behavior of the acceptance of technology.

\section{Innovation and RFID Technology Acceptance}

The application of new information technology equipment and tools, especially Internet technology including the development of mass transportation and public transportation in various aspects to be more efficient, would help the users and people to receive convenience, security and confidence in using the service. This would respond to the objectives of the organization's operations in using radio frequency identification (RFID) technology, which has presently received a lot of worldwide attention. This technology could have a high impact on businesses and individuals' daily life. Moreover, this technology can be applied to various business activities; such as, retail and wholesale marketing, production, the supply chain, logistics system, security and access control, barcode replacement, animal records and traceability. This is because RFID is an electronic data acquisition system, which has the ability to calculate and secure data. It also transmits data using electromagnetic waves instead of physical contact. As a result, users would have more convenience, as it would reduce the procedures required for storing and retrieving data from original documents. The acceptance of information technology by individuals or an organization is a guideline that can help to analyze human behavior and has also been used as an alternative way for describing intention, as well as predicting human behavior in accepting information technology more effectively (Singha and Sununtha, 2012).

In addition, research on the acceptance of information technology is the study of human behavior in order to explain the methods and reasons of each individual in accepting new information technology (Venkatesh, et al., 2003). This has been undertaken to develop a theory that predicts the behavior of individuals or organizations in accepting the use of information systems (Hevner et al., 2004). As a result, an explanation and prediction of the acceptance of information technology as well as understanding the influential factors could be a way to help and accelerate the acceptance and use of information technology by individuals or organizations ( $\mathrm{Xu}$ et al., 2004). This would include demonstrating the reasons for investing in information technology in the future. Chen and Tseng (2012) used a technology acceptance model (TAM) to study the factors that influence the intention to use web-based e-learning. The study found that Internet self-efficacy significantly affected the Perceived Usefulness and Perceived Ease of 
User. The computer anxiety of the users significantly affected the perceived usefulness and the motivation to use, which were the major factors in accepting the system. From the theory, it could be concluded that the acceptance of RFID technology and innovation would depend on the amount of time given and the technology guideline. Additionally, Davis (1989) found that there were two factors: 1) Perceived Usefulness (PU) which is the perception of the benefits that would be received and believed that they would improve their performance; such as, helping to work faster or reducing the cost. 2) Perceived Ease of User (PEOU) from Nash (2010) who found that RFID technology increased the work speed and raised efficiency (Law et al., 2000). The literature review led to the following assumptions:

Hypothesis 5: The acceptance of technology affects the efficiency of bus schedules management using radio frequency identification systems.

The model could be developed as shown in Figure 1.

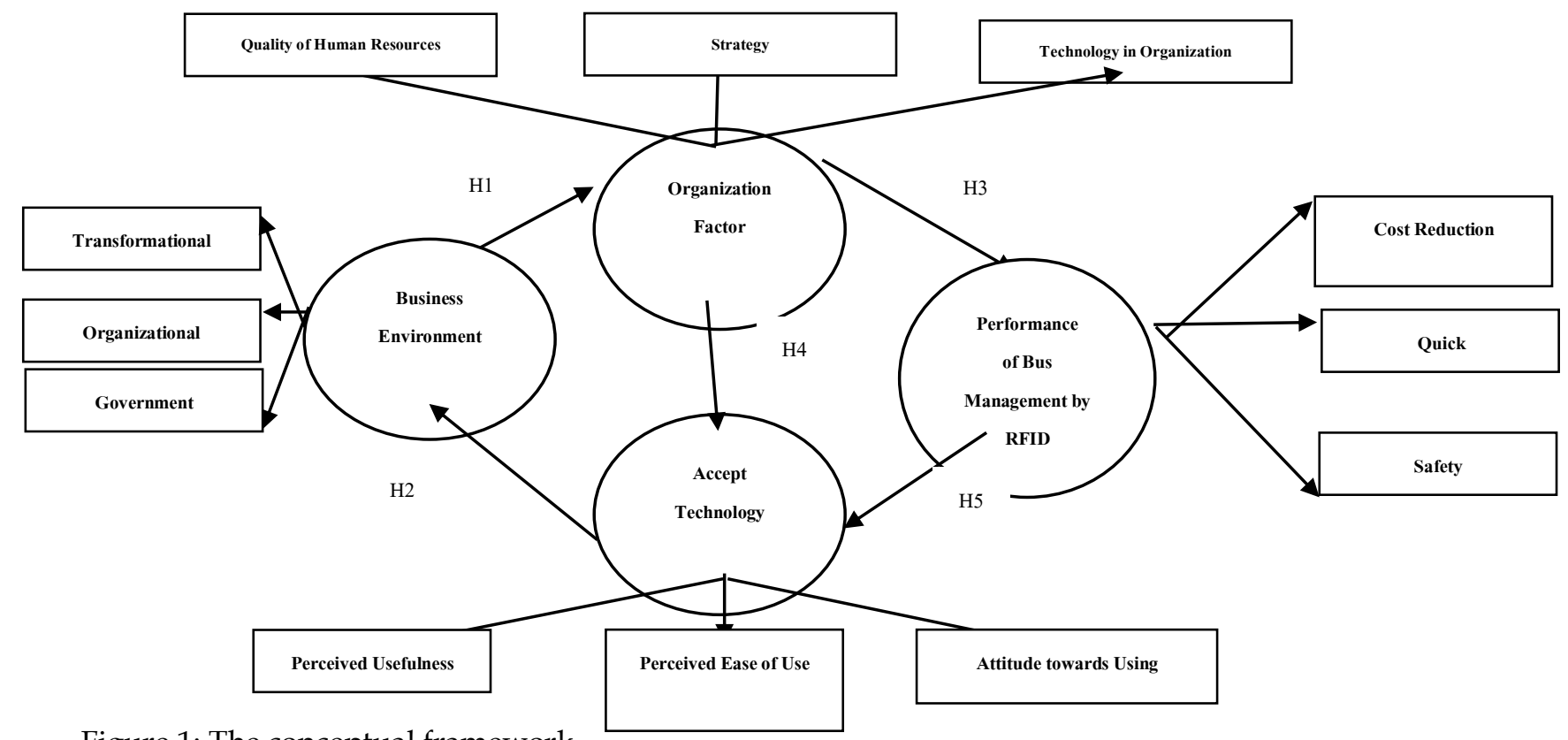

Figure 1: The conceptual framework.

Methodology

\section{Questionnaire Design}

Questionnaires were designed to measure the conceptual framework and operational definition using the standard observance of a 7-point Likert Scale to measure the consistency of Cronbach's acoefficient to calculate the average of the correlation coefficient. It was found that the a-coefficient was between $0.514-0.836$ meaning that it was reliable. If the a-coefficient was less than 0.50 , the research questions were removed.

\section{Data Collection}

The researcher used the AMOS program to analyze the correlation coefficient and apply in the structural equation model (SEM) or analyze the structural causal relationship between the correlation analysis that was analyzed by high-dimensional statistics and the correlation coefficient pattern. The researcher considered the size of the sample groups or population used in this study as 20 samples per one variable ratio. Schumacker and Lomax (2010) mentioned that SEM analysis needs a larger sample group than other forms of analysis in order to obtain an accurate result, as this provides a better representation of the population. Hair et al., (2006) stated that the sample group needs to be large enough in order to use SEM for the data analysis and data distribution in a normal curve. As such, the sample group used in this research comprised 320 Thai industrial entrepreneurs using RFID (Hair et al., 2006) and stratified random sampling. 


\section{Measurement}

\section{Dependent Variables}

The effectiveness of public transportation schedule management using RFID has the variables of cost reduction, speed and security as developed by Miguel and Brito (2011), Ngamsukkasemsri and Wiangharuthai (2011), and Rodrigues (2001).

The organizational factors have noticeable variables including the quality of the human resources, strategy, and technological system, which were developed from Kaewniyomchaisri (2013) and Martins and Terblanche (2003).

The acceptance of RFID technology has variables including the acceptance of the benefits, ease of use perception, and attitude, as developed from Chaveesuk and Wongjaturaphat (2012), Ngamsukkasemsri and Wiangharuthai (2011), and Venkatesh and Davis, (2003).

Independent Variables

The business environment has variables including the leaders of change, organizational culture, and public sector policy as previously developed by Bass (1998), Duncan (1972), and Yu and Ramanathan (2012).

\section{Research Results}

The results of the analysis for the equations of effectiveness in public transportation schedule management using RFID in Thailand were based on 320 participants. The researcher developed a model of effectiveness using RFID and testing tools with statistical methods to support and confirm the quality of the data to meet the standards of decode testing (Hair et al., 1988; Wiratchai, 1999).

\section{Data Analysis}

This research used quantitative analysis and structural equation modeling (SEM) for testing the consistency of the model and empirical data. The details are explained as follows (Hair et al., 1988; Hu and Bentley, 1999; Wiratchai, 1999):

(1) Chi-square ( $\chi 2$-test) is a statistical test used widely to test that a function is in harmony with the true zero-based assumptions and checks the model with the empirical data. If the chi-square test shows significant variance from the empirical data, that means the information is not consistent.

(2) CMIN/DF ( $\chi 2$ / df) should be less than 5.00 to show consistency with the empirical data.

(3) The comparative fit index (CFI) is considered to be consistent with the correlation. If the CFI is higher than 0.90 , that means it has consistency.

(4) The absolute fit index is popular in using two indexes that are the goodness of fit index (GFI), which indicates the amount of variance and covariance explained by the model, and the adjusted goodness of fit index (AGFI) that specifies the amount of variance and covariance explained by the model modified by the degree of independence overall. A GFI and AGFI between 0 to 1 means they are accepted when higher than 0.90 .

(5) The root means square error of approximation (RMSEA) is the statistical method used to test a hypothesis. RMSEA should be less than 0.05 or between 0.05 and 0.08 , which shows that the model is consistent with the empirical data. If between 0.08 and 0.10 , the model is less consistent with the empirical data while less than 0.10 indicates that the model is not consistent with the empirical data.

(6) The index measurement is the standardized root mean square residual (SRMR), which is a standardized residual that is the variance divided by the standard variance number of the estimated standard error. It should be less than 0.05 to show that the model is consistent with the empirical data.

\section{Results of the Structural Equation Model Analysis}

The test results of the model for effectiveness in public transportation schedule management using RFID in Thailand was considered consistent by the chi-square correlation $=\chi 2 / \mathrm{df}=1.348 \mathrm{GFI}=0.972$ AGFI $=0.947$ CFI=1.00 RMSEA=0.033, which demonstrated that the model was consistent with the 
empirical data as stated by Hair et al. (1988), Hu and Bentler (1999), Tabachnick and Fidell (2007), and Wiratchai (1999). The accepted number to analyze the model acknowledged the values of the analysis of the model with causal relations of $\chi^{2} / \mathrm{df}=<5.00$, RMSEA less than 0.05, and GFI AGFI and CFI is higher than 0.90 (refer to Table 1 and Figure 2).

Table 1. Analytics of the consistency strategy for the model with empirical data.

\begin{tabular}{llll}
\hline Index & Standard & Statistics & Results \\
\hline$X^{2 / d f}$ & $<5.00$ & 1.348 & passed \\
GFI & $>0.90$ & 0.972 & passed \\
AGFI & $>0.90$ & 0.947 & passed \\
CFI & $>0.90$ & 1.00 & passed \\
RMSEA & $<0.05$ & 0.033 & passed \\
\hline
\end{tabular}

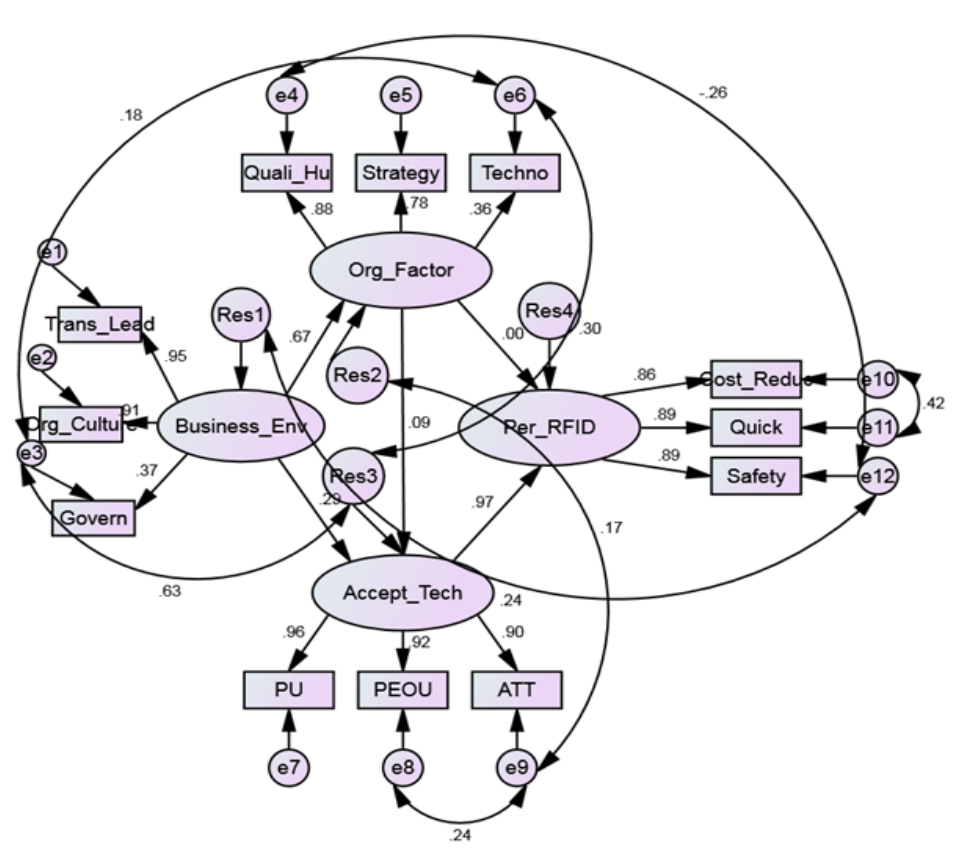

Chi-square $=55.271, \mathrm{df}=41, \mathrm{p}=.067 ; \mathrm{CMIN} / \mathrm{DF}=1.348 ; \mathrm{GFI}=.972 ; \mathrm{RMSEA}=.033$

Figure 2. Final Model

\section{Summary and Discussion}

The study found that the business environment, organizational factors and radio frequency identification (RFID) acceptance all affected the efficiency of the bus schedules management using RFID systems in Thailand. RFID technology is currently widely used in all industries. One of the applications is to improve the performance of the transport system by using RFID in bus schedules management in order to work effectively and conveniently. Moreover, the users can retrieve data and analyze that data for developing the operation to reach the maximum benefits. Since the system has recorded all the activities' data, applying RFID technology to use in the company can help to serve the customers' needs more effectively throughout the procedure and strengthen customers' confidence. The efficiency of bus schedules management using RFID systems in Thailand is a good example to show the ability in using resources in the changing process in order to achieve the organization's goal so to accomplish tasks; such as, missions, goals, policies, and objectives. This would depend on the number of employees and costs spent in that operation. The less employees and costs invested in the successful task, the more effective it would be.

This is similar to Ngamsukkasemsri and Wiangharuthai's (2011) study about the efficient development of freight trucking management with RFID. The results found that currently Thai entrepreneurs are more interested in applying RFID in their companies and the system's design, hardware

www.jbrmr.com A Journal of the Academy of Business and Retail Management (ABRM) 
and software can be developed by a Thai IT innovator, which would make the system be more flexible and suitable for an industrial working environment and domestic transportation. RFID also increases the organization's competitiveness to reach the needs of its customers effectively, strengthens the organization and reduces costs. An example of RFID technology applied in logistics management is that of SCG Logistics Management Company Limited. This is a successful project recognized domestically and internationally, which also received the Thailand ICT Excellence Award (RFID Solution for Transportation Management) in 2009 for applying RFID technology in logistics management. As a result of the development of RFID, SCG Logistics has received positive responses from both its employees and top executives in the organization together with a fast and convenient systematic operation with accurate data in which those data can be analyzed to create more effective business operations. Moreover, the transportation system in the United Kingdom uses RFID technology for payments (llie-Zudor et al., 2011) similar to the RFID Institute of Thailand (2011) that mentioned that utilizing RFID technology as a tool to manage transportation systems would help companies reduce the costs, work time in each operating point, time collecting data each day, and transit time per each round, as well as can check the operation of the transportation in real time and the number of transportation available at any time, reduce paper used and errors in data collecting. The current system can also be applied to develop any other product's system or operational procedure as well.

As such, the application of new information technology equipment and tools, especially in Internet Technology, as well as developing the mass transportation and public transportation would help the users and people have more convenience, safety and confidence. In order to meet the objectives of the organization's operation in using RFID, the employees would also be satisfied resulting in customers' satisfaction as well (Olowokudejo et al., 2011). The technology would also assist the organization to increase its ability in interacting with customers, which would lead to better service quality and faster response (Anderson, 2006; Nguyen et al., 2007). However, most of the successful companies in the global market have set their strategies that focus on the external environment and resource management which support those strategies (Yu and Ramanathan, 2012). Furthermore, Lin and Ho (2009) studied about the influence of RFID technology in the organization and environment by logistics service providers in China. The study tool was a questionnaire with the participants comprising 574 Chinese logistic companies in which the study found that $50 \%$ of the logistic companies were interested in using the technology but less than $10 \%$ had actual experience with it. Additionally, the factors of technology collection, encouragement, innovation organization, quality of human resources and government support showed a significant influence on the intention to use the technology. In the research of Dess and Beard (1984) and Miller and Friesen (1983), it was also found that the business environment was an influence on the organizational strategies. However, Yu and Ramanathan (2012) found that low operating costs, service quality, fast delivery with customers' satisfaction and a flexible organizational structure could affect strategic and organizational development.

\section{Conclusions}

The effectiveness of public transportation schedule management by using RFID in Thailand has the ability to restore the use of changing processes to effectively meet business goals. The success of operations depends on using the right person and cost. The less cost involved, the more effectiveness the organization would have. RFID can, thus, enhance the ability of the organization to compete responsibly and meet the needs of customers effectively, as well as build strength and speed in transportation and reduce the costs for the organization. Therefore, business must consider the main factors to support the effectiveness of public transportation schedule management in Thailand. Applying RFID as a tool for systems management can help reduce costs and also the hours spent for each operating point. Therefore, one-trip transportation can be checked for real-time operation immediately. As such, the systems researched and discussed can be applied to further develop production systems and processes to support other job tasks.

\section{Limitations and Future Research}


The limitation of this research is that in applying a radio frequency identification (RFID) system to public transport, it could only be studied in the viewpoint of bus operators in Thailand who use only RFID technology in their operations. Consequently, there is still a lack of case studies of all bus operators in Thailand who have not yet applied the RFID system to the public bus system. Furthermore, in the future, it is unsure whether they would decide to use the system or not. This includes the viewpoints of the service users in applying a RFID system. In this research, the researcher only investigated the industry of bus operators in Thailand. For future research, the important issues that should be examined for private agencies could include: 1) The cost analysis of RFID adoption in the public passenger car industry in Thailand; 2) bus operators in Thailand who have not yet applied the RFID system to the public transport system; 3) the needs of service users to adopt a RFID or GPS system to apply to the public transport system that often has problems of haphazard buses, lack of buses, passengers having to wait too long, problems of safety in the operation, etc., and 4) managing public transport in Thailand by the government to adopt the whole RFID system.

\section{References}

Ansoff, H., and McDonnell. (1990), Implanting Strategic Management, Prentice Hall (2nd Edition).

Anderson C, Blenkinsopp A. (2006), "Community pharmacy supply of emergency hormonal contraception: a structured literature review of international evidenc", Hum report, 21(1), pp.272-284.

Babatunde, B.O. \& Adebisi, O.A. (2012), "Strategic Environmental Scanning and Organization Performance in a Competitive Business Environment", Economic Insights - Trends and Challenges, LXIV (1/2012), pp.24-34.

Bangkok environment agency. (2009), Action plan on global warming mitigation of Bangkok 2007-2012, Bangkok: Bangkok head office.

Bass, B. M. (1998), Transformational leadership: Industrial, military, and educational impact, Mahwah, NJ: Erlbaum.

Berger, M. J., \& Forgette-Giroux, R. (2012), “Building professional learning communities. In B. Boufoy-Bastick (Ed.), The international handbook of cultures of professional development for teachers", Strasbourg: Analytics, pp. 265-284.

Chaveesuk Singha and Wongjaturaphat Sununtha. (2012), "The theory of acceptance of information technology", KMITL Information Technology Journal (Jan. - Jun. 2012).

Chen, H., \& Tseng H. (2012), "Factors that influence acceptance of web-based e-learning systems for the in-service education of junior high school teachers in Taiwan", Evaluation and Program Planning, 35(3), pp.398-406.

Davis, F.D. (1989), "Perceived Usefulness, Perceived Ease of Use, and User Acceptance of Information Technology", MIS Quarterly, 13(3), pp.319-339.

Dess, Gregory G. and Donald W. Beard. (1984), Dimensions of organizational task environments, Administrative Science Quarterly, 29, pp. 52-73.

Duncan, R.B. (1972), "Characteristics of organizational environments and perceived environmental uncertainty", Administrative Science Quarterly, 17(3), pp.313-327.

Eruemegbe, O.G. (2015), “Impact of Business Environment on Organization Performance in Nigeria: Study of Union Bank of Nigeria", European Scientific Journal November 2015 /Special/ edition, ISSN: 1857 - 7881 (Print) e - ISSN 1857- 7431.

Gibson, J.J., Edwards, T.W.D. and Prowse, T.D. (1994), "Evaporation in the north: overview of quantitative studies using stable isotopes, Mackenzie Basin Impact Study (MBIS), Interim Report\#2, S.J. Cohen (Editor), 10-14 April 1994, Yellowknife, N.W.T., pp.138-150.

Hair, Joseph F., Black, William C., Babin, Barry, Anderson, Rolph E., and Tatham, Ronald L. (2006), Multivariate Data Analysis, 6th Ed, New Jersey, Pearson Education.

Hair, J.F.J., Anderson, R.E., Tatham, R.L., Black, W.C. (1998). Multivariate Data Analysis,

5th edn, Prentice Hall, Upper Saddle River, New Jersey.

Hevner, A., S. March, J. Park, and S. Ram. (2004), "Design science in information systems research", MIS Quarterly, 28(1), pp.75-105.

Hornsby, J.S., Kuratko, D.F. \& Zahra, S.A. (2002), “Middle managers' perception of the internal environment for corporate entrepreneurship: Assessing a measurement scale", Journal of Business Venturing, 17(3), pp.253-273.

Hu, L.T. and Bentler, P.M. (1999), “Cutoff Criteria for Fit Indexes in Covariance Structure Analysis: Conventional Criteria versus New Alternatives", Structural Equation Modeling, 6(1), pp.1-55.

Johnson, G., Scholes, K., and Whittington, R. (2002), Exploring Corporate Strategy, Prentice Hall, London.

Kaasinen, E. (2009), “User Acceptance of Mobile Services", International Journal of Mobile Human Computer Interaction, $1(1)$, pp.79-97.

www.jbrmr.com A Journal of the Academy of Business and Retail Management (ABRM) 
Kaewniyomsri Wipada. (2013), "Factors that affect the organization of municipalities in Bueng Kan Province", Veridian E-Journal, Silpakorn University, 6(2), pp.501-512.

Kinyua, B.K. (2015), “Determinants of Outsourcing Services as a Cost Reduction Measure in Devolved Government: A Case Study of Nairobi City County, Kenya", European Journal of Business and Social Sciences, 4(05), August 2015, pp.12-23.

Law, C., Lee, K., and Siu, K.Y. (2000), “Efficient Memoryless Protocol for Tag Identification”, In Proceedings of the 4th International Workshop on Discrete Algorithms and Methods for Mobile Computing and Communications, pp.75-84.

L. Löfgren, B. Löfvinga, T. Pettersson, B. Ottosson, C. Rusu, S. Haasl, K. Persson, O. Vermesan, N. Pesonen, P. (2008), Enoksson, in Proceedings of Eurosensors, Dresden, Sept 2008, pp.231-234.

Lin C-Yand Ho Y-H. (2009), An Empirical Study on the Adoption of RFID Technology for Logistics Service Providers in China. International Business Research 2, 1(1).23-36.

Ilie-Zudor, E., Kemény, Z., Van Blommestein, F., Monostori, L., \& Van Der Meulen, A. (2011), “A survey of applications and requirements of unique identification systems and RFID techniques", Computers in Industry, 62(3), pp.227-252.

Margarietha, J. S. (2007), Entrepreneurial intensity: The influence of antecedents to corporate entrepreneurship in firms operating in South Africa, Philosophiae Doctor of Business management, University of Stellenbosch.

Martins, E.C, \& Terblanche, F. (2003), "Building organizational culture that stimulates creativity and innovation", European Journal of Innovation, 6(1), pp.64-74.

Miguel, P. L. S., Ledur Brito, L. A. L. (2011), “Supply Chain Management measurement and its influence on Operational Performance", Journal of Operations and Supply Chain Management, 4(2), pp.56 - 70.

Miller, D., and P.H. Friesen. (1983), "Strategy-Making and Environment: The Third Link." Strategic Management Journal 4: 221-235.

Moorhead, G. and Griffin, R. W. (1995), Organizational Behaviour, 4th Edition, Boston, Houghton Mifflin Company.

Nash, T.A. (2010), RFID Technology and Its Impact on the Supply Chain, Eastern Michigan University, Paper 243.

Ngamsukkasemsri Wiroj and Wiangharuthai Suchada. (2011), “The development of effective management for freight trucks with RFID", September 2011, Institute for the promotion of excellence in technology for RFID in Thailand.

Nguyen, T., Sherif, J. \& Newby, M. (2007), “Strategies for successful CRM implementation”, Information Management E Computer Security, 15(2), pp.102-115.

Olowokudejo, F., Aduloju, S.A., and Oke, S.A. (2011), “Corporate social responsibility and organizational effectiveness of insurance companies in Nigeria", The Journal of Risk Finance, 12(3), pp.156-167.

RFID Institute of Thailand. (2011), Development of freight truck fleet management with RFID. September 2011, pp. 125.

Rodrigo Rodrigues, Miguel Castro, and Barbara Liskov. (2001), “BASE: Using Abstraction to Improve Fault Tolerance", In Proceedings of the eighteenth ACM Symposium on Operating Systems Principles, SOSP'01, pp.15-28.

Schumacker, R. E., and Lomax, R. G. (2010), A beginner's guide to structural equation modeling. New York: Routledge.

Segal, E., Shapira, M., Regev, A., Pe'er, D., Botstein, D., Koller, D., \& Friedman, N. (2003), Module networks: identifying regulatory modules and their condition-specific Regulators from gene expression data, Nature genetics.

Singkarin Duangpun Kritchanchai and Somboonwiwat Tuanjai. (2010), Business processes for supply chain and logistics management, Bangkok: Limited partnership sunate film.

Tabachnick, B.G. and Fidell, L.S. (2007), Using Multivariate Statistics (6th edition), Boston, Allyn and Bacon.

Venkatesh, V., Morris, M.G., Davis, G.B., and Davis, F.D. (2003), “User acceptance of information Technology: Toward a unified view", MIS Quarterly, 27(3), pp.425-478.

Wiratchai Nonglak. (1999), Lisrel Model: Statistical analytics for research (Edition 3), Bangkok, Chulalongkorn.

Wheelen, T. L \& Hunger, D.J. (2012), Strategic management and business policy: toward global sustainability, 13th Ed.p. cm. Pearson Education, Inc., publishing as Prentice Hall.

Xu, S., Zhu, K. and Gibbs, J. (2004), “Global Technology, Local Adoption: A Cross Country Investigation of Internet Adoption by Companies in the United States and China", Electronic Markets, 14(1), pp.13-24.

Yu, W. \& Ramanathan, R. (2012), “Retail service quality, corporate image and behavioural intentions: the mediating effects of customer satisfaction", The International Review of Retail, Distribution and Consumer Research, 22(5), pp.485-505. 